\title{
An unusual macular lesion simulating a neoplasm
}

\author{
AMIRAM SHAPIRO, MOSHE IVRY, AND MOSHE LAHAV \\ From the Department of Ophthalmology, Hadassah University Hospital and Medical School, Jerusalem, \\ Israel
}

SUMMARY A 55-year-old woman with reticulum cell sarcoma of the stomach presented with a sudden decrease in vision and acute blood loss anaemia with thrombocytopenia. Superficial retinal haemorrhages were present in both eyes. These haemorrhages were absorbed gradually, yet a large macular mass appeared in the right eye which simulated a neoplasm. This mass disappeared over a period of a few weeks leaving minimal changes in the pigment epithelium and remarkably good visual acuity.

Flame-shaped retinal haemorrhages and cotton-wool exudates have been described in cases of anaemia of blood loss (Merin and Freund, 1968). In most cases the haemorrhages are smaller than 1 disc diameter in size, flame- or spindle-shaped, with fine striations due to their superficial location within the retinal nerve fibre layer. The cotton-wool exudates were found histopathologically to be ischaemic infarcts or so-called 'cytoid bodies' (Ashton, 1970). These retinal haemorrhages and exudates are seen when haemoglobin content is reduced to $50 \%$ or less of its normal value (Holt and Gordon-Smith, 1969). The incidence of retinal haemorrhage is increased when the anaemia is accompanied by thrombocytopenia (Rubenstein et al., 1968).

The present report is of an unusual macular mass that appeared after a macular-retinal haemorrhage.

\section{Case report}

A 55-year-old woman was admitted to our hospital with the complaint of sudden decrease of visual acuity in both eyes. Twenty-four hours before admission she had had an attack of unconsciousness, and later she passed tarry stools. Her past medical history revealed reticulum cell sarcoma of the stomach of 6 months' duration which was treated by chemotherapy (BCNU and Endoxan). Physical examination on admission showed a thin and pale patient.

Laboratory data included haemoglobin level of $6 \mathrm{~g} / \mathrm{dl}$, haematocrit of $22 \%$, white blood cell count

Address for reprints: Dr A. Shapiro, Department of Ophthalmology, Hadassah University Hospital, Jerusalem, Israel of $7000 / \mathrm{mm}^{3}\left(7 \cdot 0 \times 10^{9} / \mathrm{l}\right)$, and blood urea nitrogen of $40 \mathrm{mg} / 100 \mathrm{ml}(14 \mathrm{mmol} / \mathrm{l})$. Chest and skull $x$-rays, electroencephalograph, liver and brain scans were unremarkable. Ocular examination on admission revealed in each eye pale conjunctiva, visual acuity of $6 / 60$ and intraocular pressure of $15 \mathrm{mmHg}$ measured by Goldmann applanation tonometer. The visual fields showed central scotomas in both eyes. Fundoscopic examination disclosed retinal haemorrhages 2 to 3 disc diameters in size spread over the retinal surface in both eyes, including the macular area. The patient was treated with blood transfusion, and 4 days later the haemoglobin rose to $9.6 \mathrm{~g} / \mathrm{dl}$, haematocrit to $28 \%$, and platelets to $80000 / \mathrm{m}^{3}\left(80 \times 19^{9} / \mathrm{l}\right)$.

Two weeks later the visual acuity of the left eye improved to $6 / 9$, and fundoscopic examination showed that the haemorrhage in the macula had disappeared with partial clearing of the peripheral haemorrhages. In the right eye the visual acuity was unchanged, the peripheral retinal haemorrhages were partially absorbed, yet in the macular region a large whitish-yellow mound which bulged 4 dioptres into the vitreous was seen (Fig. 1). Fluorescein angiography showed blockage of the choroidal pattern. Over the next 3 weeks the macular mass in the right eye was gradually absorbed and the peripheral retinal haemorrhages in both eyes disappeared. One month later the only findings were residual fine pigmentary mottling in the macula of the right eye (Fig. 2). The visual acuity in this eye improved to 6/9. Repeated fluorescein angiography revealed window defects in the macular area (Fig. 3). On follow-up examination 6 months later the visual acuity and ophthalmic appearance remained unchanged. 


\section{Discussion}

Retinal haemorrhages are commonly found after an acute bleed, while retinal exudates tend to occur after chronic intermittent blood loss (Holt and Gordon-Smith, 1969). The exact aetiology of these retinal lesions is still unknown, yet focal retinal anoxia plays a major role in the formation of

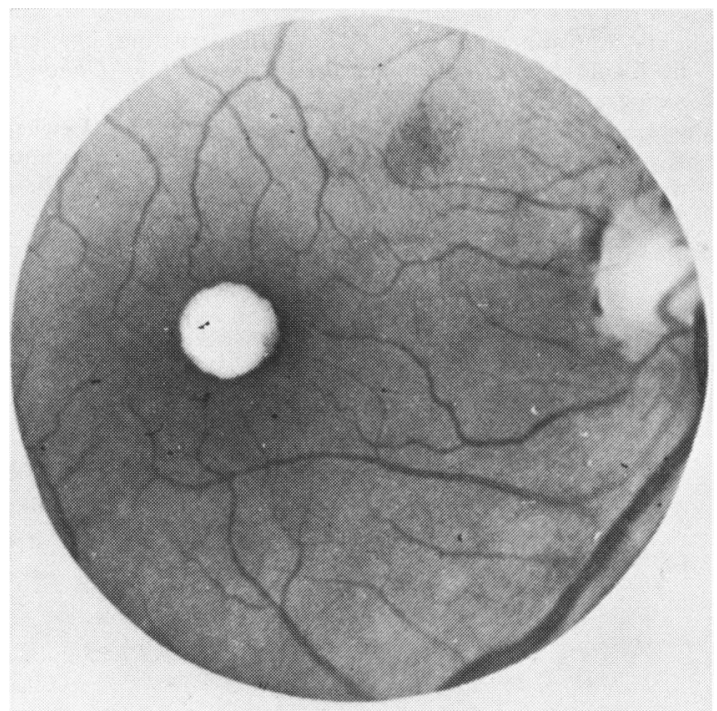

Fig. 1 Clinical fundus photograph of the right macular region. A well circumscribed pale lesion is clearly seen

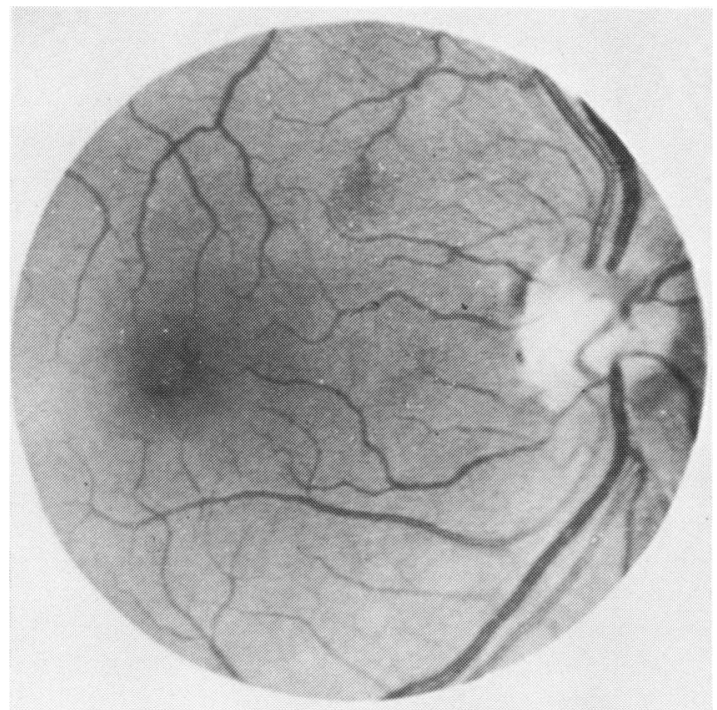

Fig. 2 Clinical fundus photograph of the right macular region after recovery of the visual acuity, with fine pigment epithelial defects in the foveal region

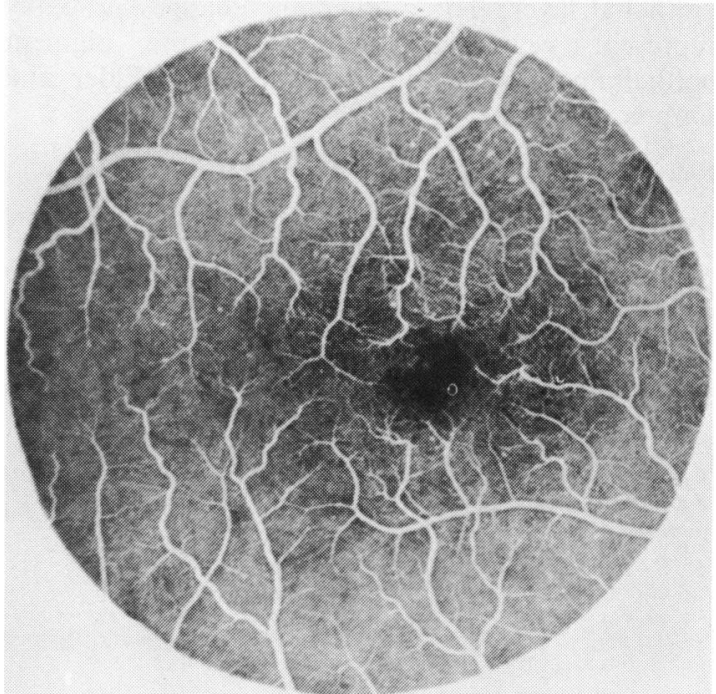

Fig. 3 Fluorescein angiography of the right macular region after recovery of visual acuity (venous phase). Note few inferotemporal pigment epithelial defects with 'window effects' in the fovea and a few drusen in the posterior pole. (Exciting filter Baired Atomic B4 with barrier filter Kodak Wratten 15.)

haemorrhages and cotton-wool exudates (Pears and Pickering, 1960). With intact internal limiting membrane the retinal haemorrhages clear up completely without leaving any traces (Ballantyne and Michaelson, 1970). When the bleeding is profuse the broken down products are more slowly removed by phagocytosis (Shakib and Ashton, 1966), and it may later lead to the formation of lipoid deposits, which will appear as small hard exudates (Leishman, 1957). At times retinal haemorrhages which remain for a longer period of time may be associated with scarring and glial proliferation (Duke-Elder and Dobree, 1967).

The remarkable finding in the present case is the appearance of a macular mass which simulated a neoplasm during the absorption process of a macular retinal haemorrhage. The possibility of a metastatic lesion from the reticulum cell sarcoma had to be considered in the differential diagnosis. Metastases from reticulum cell sarcoma to the choroid have been reported, but their appearance was of a flat choroidal infiltrate rather than a dome-shaped tumour (Vogel et al., 1968). In addition the blockage of choroidal pattern seen in fluorescein angiography and the resolution of this lesion over a short period of time ruled out the presence of a metastasic lesion. It is interesting to note the benign outcome of this large haemorrhage, with remarkably good recovery of visual acuity and minimal damage to the pigment 
epithelial layer. The pigmentary changes probably represent wandering cells from the pigment epithelium into the retinal tissue (Duke-Elder and Dobree, 1967).

\section{References}

Ashton, N. (1970). Pathophysiology of retinal cotton-wool spots. British Medical Bulletin, 26, 143-150.

Ballantyne, A. J., and Michaelson, I. C. (1970). Textbook of the fundus of the eye, 2nd edn., pp. 138-139, 287-288. Livingstone: London.

Duke-Elder, S., and Dobree, H. (1967). System of Ophthalmology, Vol. 10, Diseases of the Retina, pp. 61-63, 144-145. Henry Kimpton: London.

Holt, J. M., and Gordon-Smith, E. C. (1969). Retinal abnormalities in diseases of blood. British Journal of Ophthalmology, 53, 145-160.
Leishman, R. (1957). The eye in general vascular disease. Hypertension and arteriosclerosis. British Journal of Ophthalmology, 41, 641-701.

Merin, S., and Freund, M. (1968). Retinopathy in severe anaemia. American Journal of Ophthalmology, 66, 11021106.

Pears, A. M., and Pickering, G. W. (1960). Changes in the fundus oculi after haemorrhage. Quarterly Journal of Medicine, 29, 153-178.

Rubenstein, R., Yanoff, M., and Albert, D. (1968). Thrombocytopenia, anaemia and retinal haemorrhage. American Journal of Ophthalmology, 65, 435-439.

Shakib, M., and Ashton, N. (1966). Ultrastructural changes in focal retinal ischaemia. British Journal of Ophthalmology, 50, 325-384.

Vogel, M. H., Font, R. L., Zimmerman, L. E., and Levine, R. A. (1968). Reticulum cell sarcoma of the retina and uvea. American Journal of Ophthalmology, 66, 205-215. 